\title{
Mineralization and Osteoblast Cells Response of Nanograde Pearl Powders
}

\author{
Jian-Chih Chen, ${ }^{1}$ Jung-Chang Kung, ${ }^{2}$ Chih-Hsin Hsieh, ${ }^{1}$ Mei-Ju Hou, ${ }^{3}$ \\ Chi-Jen Shih, ${ }^{3}$ and Chun-Cheng Hung ${ }^{4,5}$ \\ ${ }^{1}$ Department of Orthopaedics, Kaohsiung Medical University Hospital, Kaohsiung Medical University, Kaohsiung 807, Taiwan \\ ${ }^{2}$ Department of Family Dentistry, Kaohsiung Medical University Hospital, Kaohsiung Medical University, Kaohsiung 807, Taiwan \\ ${ }^{3}$ Department of Fragrance and Cosmetic Science, Kaohsiung Medical University, 100 Shi-Chuan 1st Road, Kaohsiung 80708, Taiwan \\ ${ }^{4}$ School of Dentistry, College of Dental Medicine, Kaohsiung Medical University, Kaohsiung 807, Taiwan \\ ${ }^{5}$ Department of Prosthodontics, Kaohsiung Medical University Hospital, Kaohsiung Medical University, Kaohsiung 807, Taiwan
}

Correspondence should be addressed to Chi-Jen Shih; cjshih@kmu.edu.tw and Chun-Cheng Hung; chuchh@cc.kmu.edu.tw

Received 10 March 2013; Revised 7 May 2013; Accepted 7 May 2013

Academic Editor: Eng San Thian

Copyright (c) 2013 Jian-Chih Chen et al. This is an open access article distributed under the Creative Commons Attribution License, which permits unrestricted use, distribution, and reproduction in any medium, provided the original work is properly cited.

\begin{abstract}
The main objective of this study is to characterize the thermal, mineralization, and osteoblast cells response of pearl nanocrystallites. The results obtained from X-ray diffraction, FTIR spectra demonstrate that the pearl nano-crystallites can induce the formation of an HA layer on their surface in SBF, even after only short soaking periods. The in vitro cell response to nano-grade pearl powders is assessed by evaluating the cytotoxicity against a mouse embryonic fibroblast cell line and by characterizing the attachment ability and alkaline phosphatase activity of mouse bone cells (MC3T3-E1, abbreviated to E1) and bone marrow stromal precursor (D1) cells. The cytotoxicities of pearls were tested by the filtration and culture of NIH-3T3 mouse embryonic fibroblast cells. The viability of the cultured cells in media containing pearl crystallites for 24 and $72 \mathrm{~h}$ is greater than $90 \%$. The bone cells seen in these micrographs are elongated and align predominately along the pearl specimen. The cells observed in these images also appeared well attached and cover the surface almost completely after $1 \mathrm{~h}$. The pearl nanocrystallites had a positive effect on the osteogenic ability of ALP activity, and this promoted the osteogenic differentiation of MSCs significantly at explanations.
\end{abstract}

\section{Introduction}

Pearl, which is composed of nacre, is produced in an active physiological environment by molluscs. Pearl, nacre, and bone are all biomineralization products of organisms. Pearl and nacre are basically composed of calcium carbonate (aragonite, $\mathrm{CaCO}_{3}$ ), whereas bone mainly consists of calcium phosphate or hydroxyl apatite (HA); although their components are different, parts of the complex machineries that direct their formation may be homologous $[1,2]$. Nacre has been reported to contain one or more signal molecules $[3,4]$ similar to bone morphogenetic proteins (BMPs), bone growth factors present in human bone that can activate the osteogenic bone marrow cells both in vivo and in vitro and lead to bone formation. Atlan et al. [5] conducted an important bone repair experiment of eight female patients using nacre powder, finding that osteoblasts were clearly attracted to the nacre, and new bone formed throughout the implanted material after six months. This activity is thought to be due to the similarity between the growth proteins present in nacre and those in bone. Nacres are considered suitable natural materials for dental and bone restorations [6-13]. In addition to their worldwide availability and low cost, they can initiate and induce mineralized tissue formation by human osteoblasts in vitro, and they also exhibit osteogenic and osteoinductive features due to their ability to bond with bone. At present, nacre is considered a promising osteoinductive material. Pearl contains more organic substances and trace elements, so it is expected that pearl will show better osteogenic activity than shell nacre since it is a natural carrier of bone growth factors. Moreover, pearls are currently cultured on a large scale in many countries, so 
pearls are now commercially available at an affordable price [14].

In this study, morphology evaluation using the Brunauer, Emmett, and Teller (BET) method was performed in conjunction with high resolution transmission electron microscope (HRTEM). The mineralization of pearl powders was tested by immersing the pearl samples in simulated body fluid (SBF). The formation of a crystalline phase on the surface of the pearls was identified by scanning electron microscopy and X-ray diffraction. The in vitro cell response to nanograde pearl powders is assessed by evaluating the cytotoxicity against a mouse embryonic fibroblast cell line and by characterizing the attachment ability and alkaline phosphatase activity of mouse bone cells (MC3T3-E1, abbreviated to E1) and bone marrow stromal precursor (D1) cells.

\section{Experimental Procedure}

2.1. Nanograde Pearl Crystallite Preparation. The nanoparticles were prepared using the wet polish method with a ball grinding machine (Just Nanotech Co., JBM-B035, Taiwan). A mixture of dry ingredients composed of $8 \mathrm{~g}$ of pearl powder and $1.6 \mathrm{~g}$ of dispersant was added to $240 \mathrm{~mL}$ of deionized water to make slurry. The slurry was premixed for $1.5 \mathrm{~h}$ and then placed in a grind chamber with $500 \mathrm{~g}$ of $0.1 \mathrm{~mm}$ zirconium particles for $1.0 \mathrm{~h}$ at $2000 \mathrm{rpm}$. After grinding, the slurry was passed through a 200 mesh sieve to remove the larger particles. The slurry was then dried by freezedrying at $218 \mathrm{~K}$ under vacuum. The original morphologies of the specimens were characterized by scanning electron microscopy (SEM) as shown in Figure 1.

2.2. Thermal Characterization. Differential thermal and thermogravimetric analyses (DT/TGA) were conducted on powder samples in $50 \mathrm{mg}$ quantities at heating rates of $5^{\circ} \mathrm{C} / \mathrm{min}$. Samples were heated from $25^{\circ} \mathrm{C}$ to $1200^{\circ} \mathrm{C}$ in air. Crystalline phases were identified using X-ray diffraction (XRD) analysis. XRD was performed using an X-ray diffractometer with $\mathrm{Cu} \mathrm{K} \alpha$ radiation and a Ni filter operated at $30 \mathrm{kV}$ and $20 \mathrm{~mA}$, with a scanning rate of $4^{\circ} / \mathrm{min}$. Fourier transform infrared (FTIR) absorption spectra were obtained with a spectral resolution of $4 \mathrm{~cm}^{-1}$. For FTIR, each sample was mixed with $\mathrm{KBr}$ (in a 1:10 glass : $\mathrm{KBr}$ mass ratio) and pressed into a $200 \mathrm{mg}$ pellet with a diameter of $12 \mathrm{~mm}$. Infrared absorption spectra were obtained over the frequency range of 400$4000 \mathrm{~cm}^{-1}$. Composite spectra presented for each sample represent an average of 64 scans, normalized to the spectrum of a blank $\mathrm{KBr}$ pellet. The specific surface areas of the samples were measured using the conventional BET method (ASAP 2010, Micromeritics, USA) with nitrogen as the absorbent.

2.3. In Vitro Bioactivity Test. The mineralization of the pearl powders was assessed in a simulated body fluid (SBF) similar to human plasma [15]. The in vitro bioactivity of the powders was tested by immersing the samples in simulated body fluid (SBF) at a solid: liquid ratio of $1 \mathrm{mg} / \mathrm{mL}$ at $37^{\circ} \mathrm{C}$. The formation of hydroxyapatite on the surface of the sample was

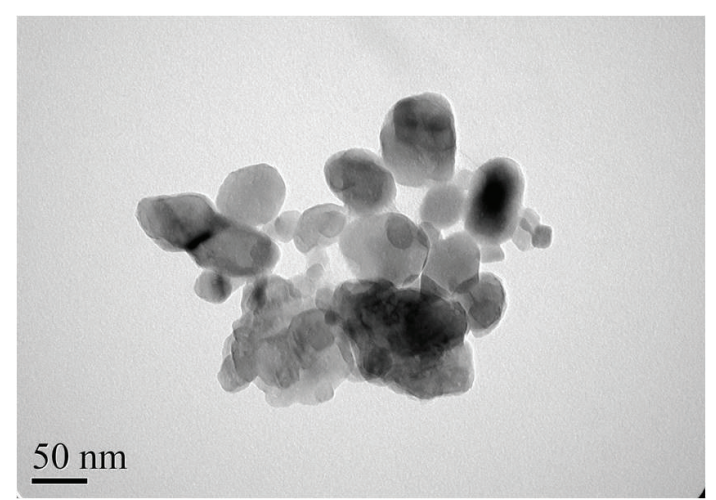

FIGURE 1: TEM image of ground pearl powders.

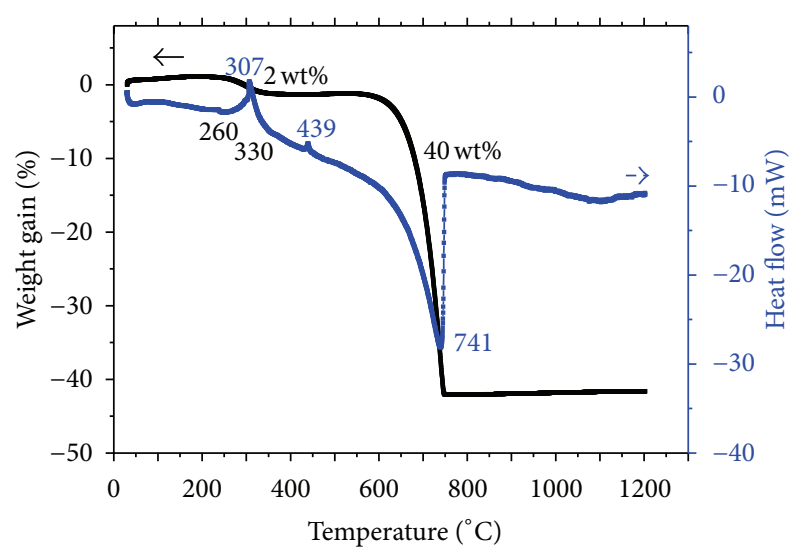

FIGURE 2: DTA/TGA curves of pearl powders at a heating rate of $5^{\circ} \mathrm{C} / \mathrm{min}$ in air.

studied as a function of time. The crystalline phase was identified by scanning electron microscopy ((SEM) Philips XL40 FE-SEM) and X-ray diffraction ((XRD) Shimadzu, XRD$6000)$. XRD was performed using an X-ray diffractometer with $\mathrm{Cu} \mathrm{K} \alpha$ radiation and a Ni filter operated at $30 \mathrm{kV}, 20 \mathrm{~mA}$ and a scanning rate of $4^{\circ} \mathrm{min}^{-1}$.

2.4. Cytotoxicity of Pearl Powders. The cytotoxicities of the MBGs were tested by filtration and culture of the fibroblast cells (NIH 3T3, abbreviated 3T3). The cells were provided by the National Institute of Health (NIH) in Taiwan. The 3T3 cells were derived from newborn mouse fibroblasts and cultured in Dulbecco's modified Eagle's medium (DMEM) (Gibco, Invitrogen Taiwan Ltd., MD) containing 10\% bovine serum (BS) (Biological Industries, Haemek, Israel). An XTT Cell Viability Assay Kit provided a simple method to count live cells using an absorbance reader. The cells' adhesive and reproductive abilities were measured at two early stages: $24 \mathrm{~h}$ and $72 \mathrm{~h}$. After the cultured time, the cells on the sample surface were washed with phosphate-buffered saline (PBS) and transferred to $200 \mu \mathrm{L}$ of culture medium with a $100 \mu \mathrm{L}$ XTT kit and were incubated for another $4 \mathrm{~h}$. The reaction medium was then measured spectrophotometrically at $490 \mathrm{~nm}$ using an ELISA microplate reader UVM-340 (ASYS Hitech GmbH, Eugendorf, Austria). Finally, the cell 


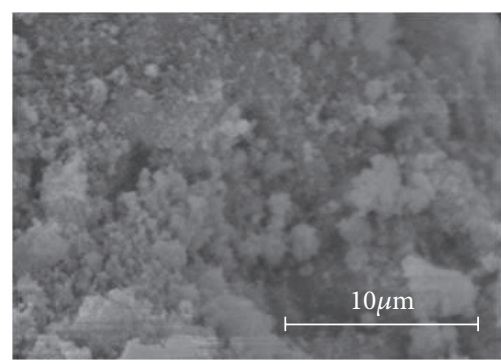

(a)

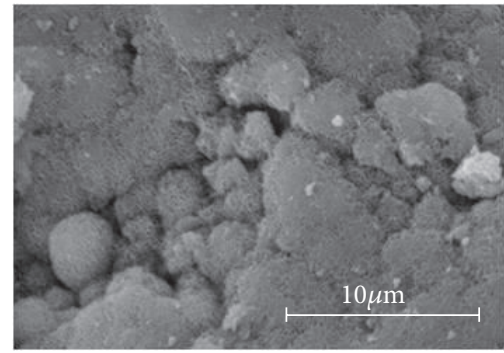

(c)

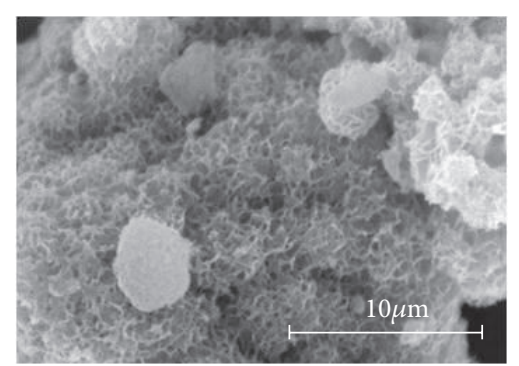

(b)

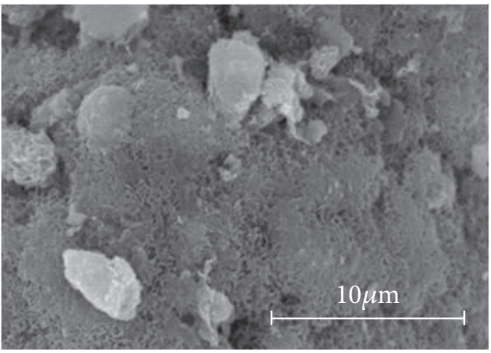

(d)

FIGURE 3: FE-SEM micrograph spectra of pearl powders before (a) and after being immersed in SBF for (b) $4 \mathrm{~h}$, (c) $6 \mathrm{~h}$, and (d) $24 \mathrm{~h}$.

numbers were determined from a plot of absorbance (OD values) versus the $3 \mathrm{~T} 3$ cells after adjustment via XTT assays. Each experiment was performed five times $(n=5)$. The statistical analyses of the results were analyzed using oneway ANOVA to investigate the significant group comparisons between different populations using the JMP 9.0 software (SAS Institute, Inc., Cary, NC, USA). In all cases, the results were considered to be significantly different when $P<0.05$.

2.5. Cell Seeding and SEM Specimen Preparation. E1 cells were cultured on pearl disks placed in a 96-well culture plate at an initial density of $1 \times 10^{5} \mathrm{cells} / \mathrm{cm}^{2}$. The cells were incubated for $1,24,72$, and $168 \mathrm{~h}$. The pearl disks were then fixed in a $25 \%$ glutaraldehyde, $4 \%$ paraformaldehyde matrix for $1 \mathrm{~h}$ at $4^{\circ} \mathrm{C}$. The cells were washed in wash buffer containing $4 \%$ sucrose in PBS and postfixed in 1\% osmium tetroxide in PBS for $1 \mathrm{~h}$ at $4^{\circ} \mathrm{C}$. The samples were then dehydrated sequentially in graded ethanol (30\%, 50\%, 70\%, 95\%, and $100 \%$ ethanol). The specimens were dried in hexamethyldisilazane (HMDS) for $3 \mathrm{~min}$ before they were coated with gold for SEM analysis. The morphological characteristics of the cells attached to the pearl disks were determined using field-emission SEM. To quantitatively evaluate the E1 cells adhered to the pearl disks over time, an alamarBlue assay kit (AbD Serotec, Oxford, UK) was used. After 1, 24, 72, and $168 \mathrm{~h}$, the tested samples were washed with PBS and moved to a new plate. Then, $500 \mathrm{~mL}$ of culture medium and $50 \mathrm{~mL}$ of alamarBlue were added to the samples, and the samples were incubated for $2 \mathrm{~h}$. After incubation, $100 \mathrm{~mL}$ of the reactants were extracted and measured using the ASYS UVM 340 microplate reader. The absorbance values of the reactants $(n=5)$ were monitored at 570 and $600 \mathrm{~nm}$. After $30 \mathrm{~min}$, the reaction was stopped by adding solutions of $25 \mu \mathrm{L}$ of $3 \mathrm{M} \mathrm{NaOH}$. The statistical analyses of the results were analyzed using oneway ANOVA to investigate the significant group comparisons between different populations using the JMP 9.0 software (SAS Institute, Inc., Cary, NC, USA). In all cases, the results were considered to be significantly different when $P<0.05$.

2.6. Osteogenic Evaluations. The ALP and TRAP activities were detected using a TRACP and ALP Double-Staining Kit (TaKaRa Bio Inc., Shiga, Japan) according to the manufacturer's instructions. Elevation in ALP activity in D1 cells reflects those osteogenic cells that were undergoing terminal differentiation. D1 cells were seeded at $1 \times 10^{5}$ cell/well in a 48-well plate. Cells were cultured for 1, 24, 72, and $168 \mathrm{~h}$. D1 cells were harvested and washed with PBS. After washing, solutions of $500 \mu \mathrm{L}$ p-nitrophenyl phosphate (FASTTM pNPP Substrate Tablet Set (Sigma Chemical Co., Poole, Dorset, UK) in $0.05 \mathrm{M}$ Tris buffer) were added to the wells. After $30 \mathrm{~min}$, the reaction was stopped by adding $25 \mu \mathrm{L}$ $3 \mathrm{M} \mathrm{NaOH}$. Absorption was measured at $405 \mathrm{~nm}$.

\section{Results and Discussion}

3.1. Morphology and Thermal Behavior of Pearl Crystallites. The morphology of the milled pearl crystallites was characterized by transmission electron microscopy (TEM) as shown in Figure 1. The ultrafine particle size was less than $100 \mathrm{~nm}$, and the specific surface area of the pearl crystallites $\left(\mathrm{N}_{2}\right.$, BET) was found to be $28.9 \mathrm{~m}^{2} / \mathrm{g}$. DTA/TG heating curves of pearl powders measured at a heating rate of $5^{\circ} \mathrm{C} / \mathrm{min}$ from $25^{\circ} \mathrm{C}$ to $1200^{\circ} \mathrm{C}$ are shown in Figure 2. There is an endothermic peak at about $307^{\circ} \mathrm{C}$ accompanied by a $2 \%$ weight loss ascribed to the organic species of the materials included in the pearl powder. This observation provides 
further evidence that pearl is not entirely inorganic, with protein molecules incorporated into each layer $[15,16]$. The exothermic peak at $439^{\circ} \mathrm{C}$ is due to the aragonite to calcite transformation of the $\mathrm{CaCO}_{3}$ nanoparticles. During the heating from 580 to $750^{\circ} \mathrm{C}$, the weight loss and exothermic peak around $741^{\circ} \mathrm{C}$ are ascribed to the decomposition of $\mathrm{CO}_{2}$.

3.2. Mineralization of Pearl Nanocrystallites In Vitro. One significant characteristic of bioactive materials is their ability to bond with living tissue, in this case bone. Bonding occurs through the formation of an HA interface layer on the surface, both in vitro and in vivo [17]. The in vitro bioactivity of the pearl nanocrystallites was investigated by soaking them in simulated body fluid. SEM images of the pearl before and after soaking in SBF for $4 \mathrm{~h}, 6 \mathrm{~h}$, and $24 \mathrm{~h}$ are shown in Figure 3. The pearl surface was smoothed before soaking in SBF. The surfaces of these pearls show important changes after soaking in SBF for $4 \mathrm{~h}$. The surface was fully covered with a layer of needle-shaped crystallites. Furthermore, the thickness of the HA layer and the spherical particles with needle-like crystallites increases with increasing soaking times. The above results indicate that these pearls can induce the formation of an HA layer on their surface in SBF even for short soaking periods, which demonstrates the excellent in vitro bone forming bioactivity of pearls. The XRD patterns of the pearl powders before and after soaking in SBF are shown in Figure 4, which indicate the aragonite phase of $\mathrm{CaCO}_{3}$ before soaking. After soaking in SBF for $4 \mathrm{~h}$, two diffraction peaks at $31.7^{\circ}$ and $25.8^{\circ}$ appeared, corresponding to the (211) and (002) reflections of hydroxide apatite. Figure 5 summarizes the FTIR spectra of the pearl powders before and after soaking in SBF. Before soaking, the $\mathrm{CO}_{3}{ }^{2-}$ ion bending and stretching vibrations that give rise to absorption at $700-864$ and $844-1090 \mathrm{~cm}^{-1}$ are present. The strong IR band detected at $1792 \mathrm{~cm}^{-1}$ could also be attributed to the $\mathrm{C}=\mathrm{O}$ groups of the carbonate ions. After $4 \mathrm{~h}$ of soaking in $\mathrm{SBF}$, the band at $603 \mathrm{~cm}^{-1}$ split into a doublet at 562 and $603 \mathrm{~cm}^{-1}$, corresponding to a crystalline phosphate. This agrees with the results of the XRD patterns. After soaking in SBF for $4 \mathrm{~h}$, reflections of hydroxide apatite appeared. Similar phenomena have also been observed in the in vitro osteogenic activity of pearl [14]. HA can be formed on pearl surface in SBF based on a dissolution-binding-precipitation mechanism. HRTEM analysis provides direct microstructural evidence for poorly crystallized HA, it indicates that there are so many arranged dislocations and shuttle-like amorphous areas in HA particles, and calcium surplus in HA crystal structure is found, which implies that HA is formed on pearl surface in their study [14].

3.3. Cytotoxicity of Nanograde Pearl Crystallites. The in vitro cell response was assessed by evaluating the cytotoxicity of these materials against the mouse embryonic fibroblast cell line. Cell proliferation in the presence of nanograde pearl crystallites was evaluated using an XTT assay. Cells were assessed in both the absence and presence of nanograde pearl crystallites as a function of culture time. NIH-3T3 mouse

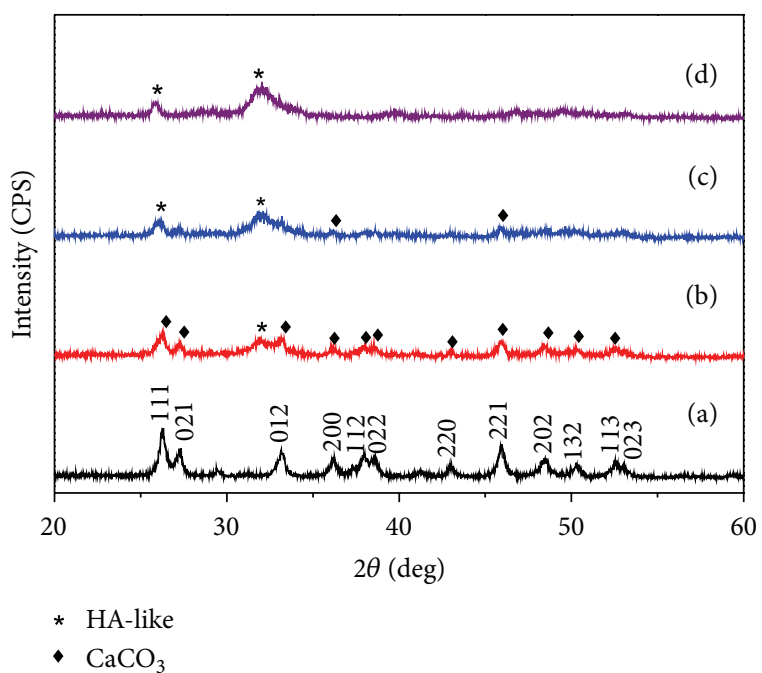

FIGURE 4: XRD patterns of pearl powders before (a) and after being immersed in SBF for $4 \mathrm{~h}$ (b), $6 \mathrm{~h}$ (c), and $24 \mathrm{~h} \mathrm{(d).}$

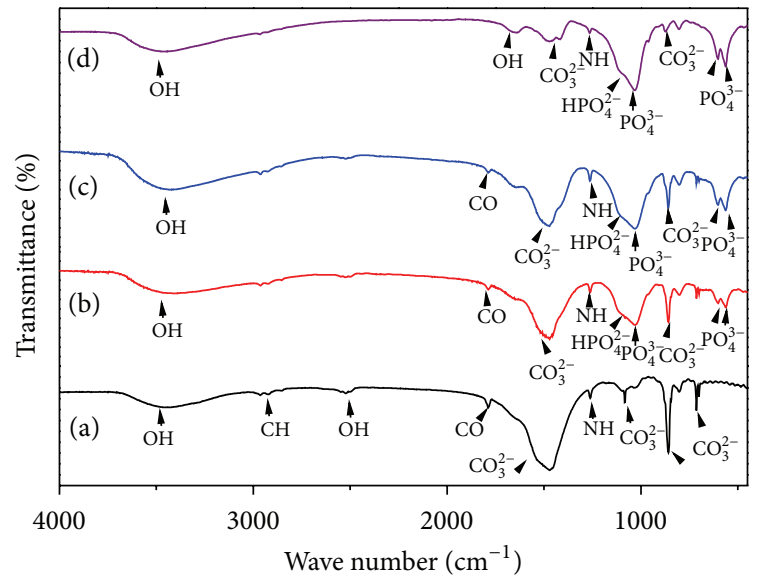

FIGURE 5: FTIR spectra of pearl powders (a) before and after being immersed in SBF for (b) $4 \mathrm{~h}$, (c) $6 \mathrm{~h}$, and (d) $24 \mathrm{~h}$.

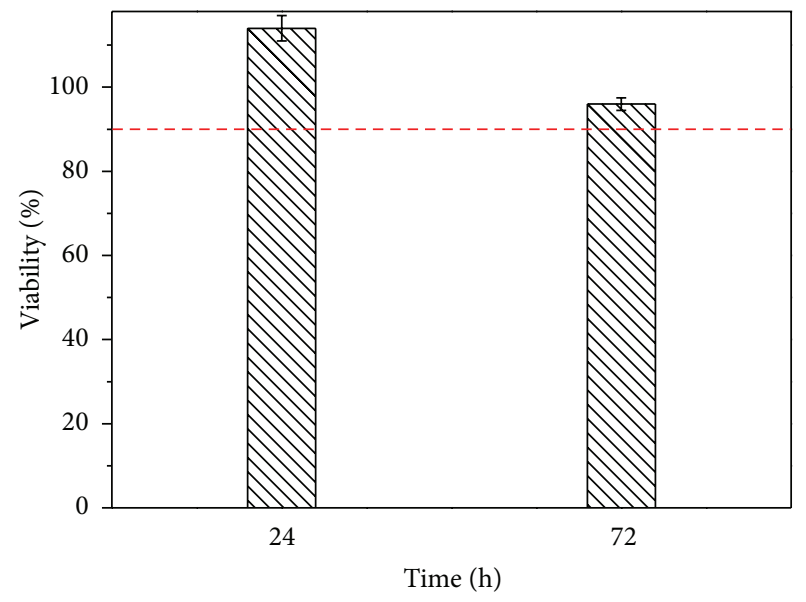

MIV Pearl

FIGURE 6: Viability of NIH-3T3 cells for various durations cultured for $72 \mathrm{~h}$ and immersed in the media. $(n=5, P<0.05)$. 

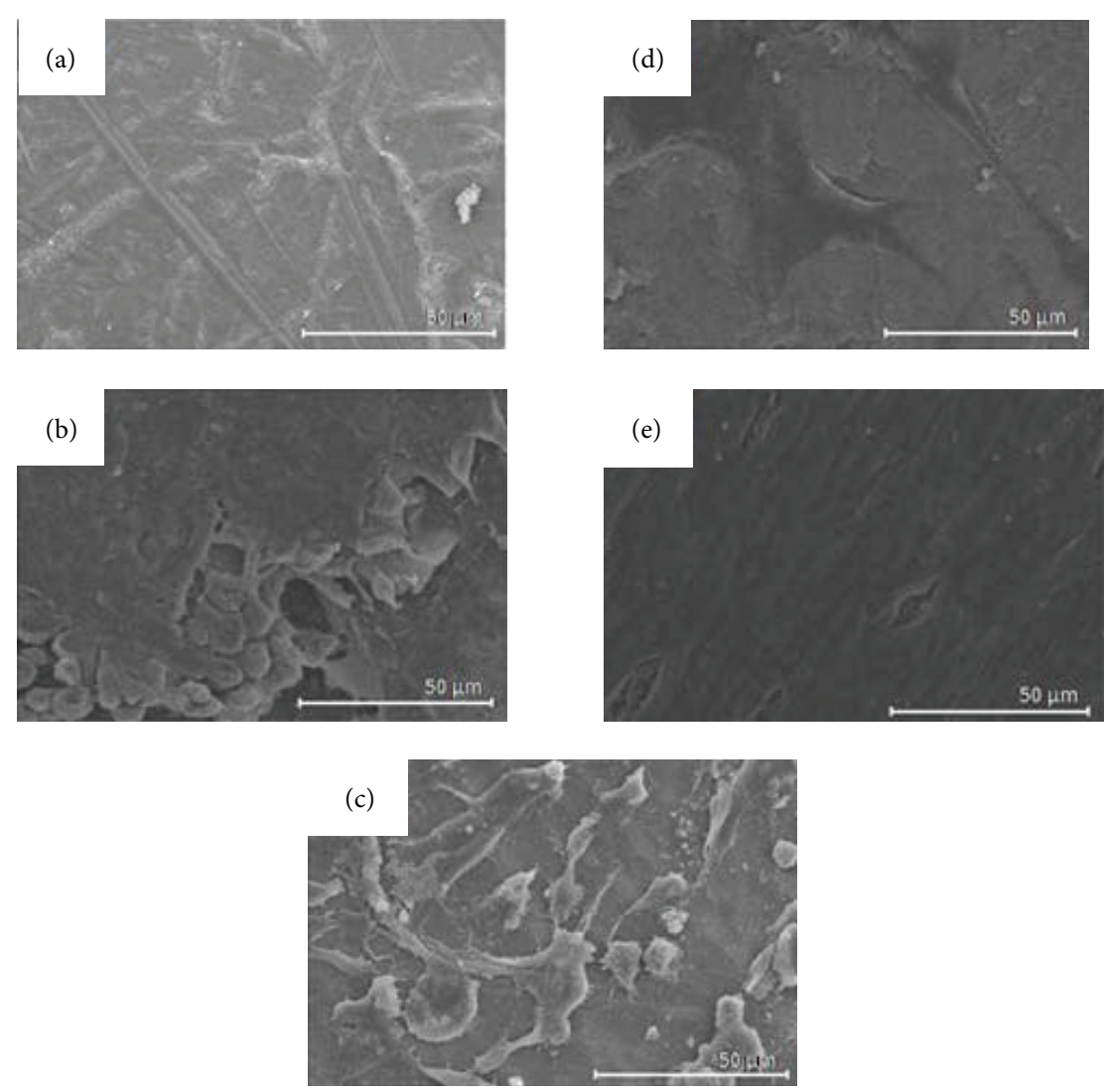

FIGURE 7: SEM images of the attachment of MC3T3-E1 cultured on pearls: (a) initial, (b) $1 \mathrm{~h}$, (c) $24 \mathrm{~h}$, (d) $72 \mathrm{~h}$ and (e) $168 \mathrm{~h}$.

embryonic fibroblast cells were cultured in media containing pearl crystallites for 24 and $72 \mathrm{~h}$, as depicted in Figure 6. As the culture time increased from 24 to $72 \mathrm{~h}$, the viability of the cultured cells did not change considerably. The viability of the cultured cells in media containing pearl crystallites for 24 and $72 \mathrm{~h}$ is greater than $90 \%$.

\subsection{Bone Cell Attachment onto Pear Disks. The cells were cul-} tured for $1,24,72$, and $168 \mathrm{~h}$ each to determine their adhesive and initial proliferative abilities. Figure 7 indicates that the E1 cells adhere to the pearl disks in different stages. Initially, the osteoblastic cells seen in these micrographs are elongated, with alignment predominately along the specimen. The cells shown in these images appear well attached and almost completely cover the surface after $1 \mathrm{~h}$. To quantitatively investigate the E1 cells adhered to pearl disks over time, the number of cells was monitored as a function time, as illustrated in Figure 8. A significant increase initially from $5.68 \times 10^{4}$ to $8.81 \times 10^{4}$ (about $55 \%$ increases) from $1 \mathrm{~h}$ to $24 \mathrm{~h}$. There are not many differences between $24 \mathrm{~h}$ and $72 \mathrm{~h}$ and abruptly increased to $1.13 \times 10^{5}$ (about 99.2\% increases) between $72 \mathrm{~h}$ and $168 \mathrm{~h}$. Based on the above-mentioned results, it is therefore believed that pearls can facilitate bone cell adhesion, differentiation, and proliferation.

3.5. Osteogenic Evaluations. The ALP activities were significantly larger over time when compared with the initial

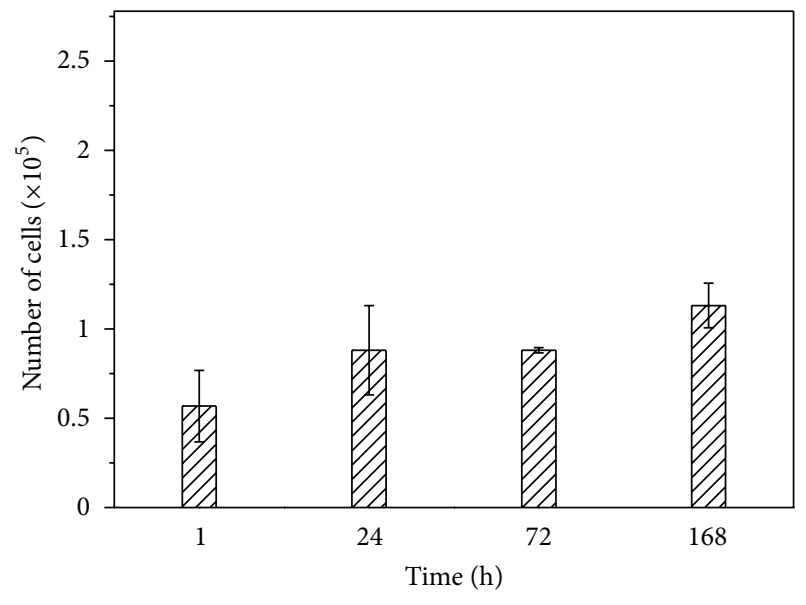

NIV Pearl

FIGURE 8: MC3T3-E1 cell numbers were counted after (a) $1 \mathrm{~h}$ (b) $24 \mathrm{~h}$ (c) $72 \mathrm{~h}$, and (d) $168 \mathrm{~h} .(n=5, P<0.05)$.

time points. The examination of ALP quantities via staining confirmed this phenomenon. A longer incubation time greatly increased the level of ALP (Figure 9). To quantitatively investigate the ALP activities to pearl disks over time, the ALP activities were monitored as a function time, as illustrated in Figure 10. The ALP activities significantly increased initially 

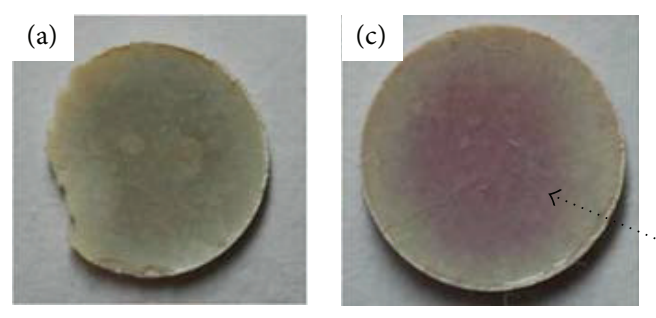

Purple area
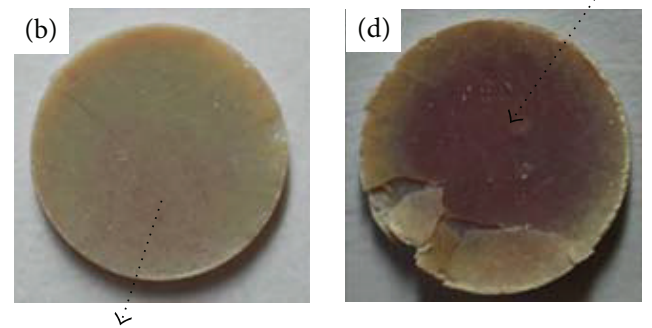

Purple area

FIGURE 9: Light photos of the pearl promoted the ALP activity of cell line D1 at (a) initial (b) $24 \mathrm{~h} \mathrm{(c)} 72 \mathrm{~h}$ and (d) $168 \mathrm{~h}$.

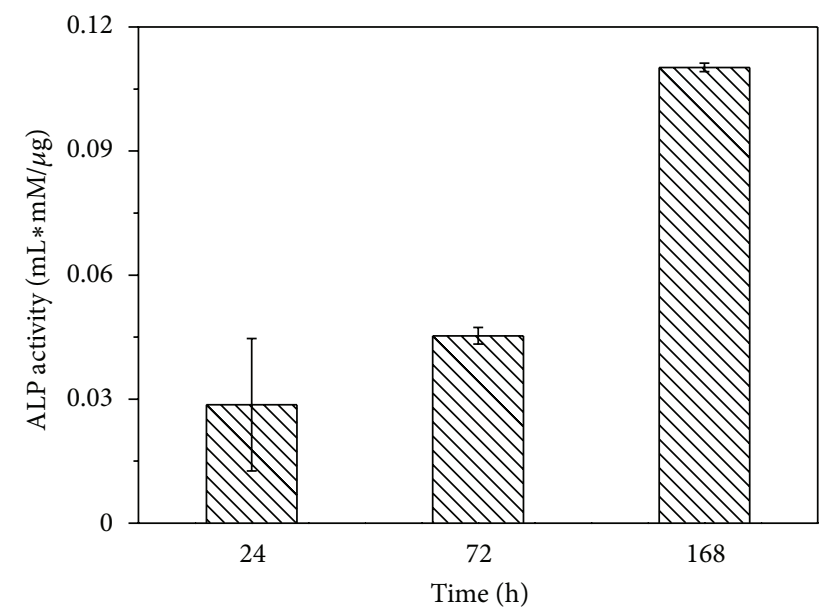

QIV Pearl

FIgure 10: Pearl promoted the ALP activity of cell line D1 at $24 \mathrm{~h}$, $72 \mathrm{~h}$ and $168 \mathrm{~h} .(n=5, P<0.05)$.

from 0.029 to 0.045 in the range of $24 \mathrm{~h}$ to $72 \mathrm{~h}$ and then increased to 0.11 between $72 \mathrm{~h}$ and $168 \mathrm{~h}$. Our results show that the pearl nano-crystallites had a large positive effect on osteogenic ALP activity, and this promoted the osteogenic differentiation of MSCs significantly at explanations.

\section{Conclusion}

The main objective of this study is to characterize the morphology, mineralization, and osteoblast cells response of pearl nano-crystallites. Results are summarized as follows.

(1) DTA/TG heating showed an endothermic peak at about $307^{\circ} \mathrm{C}$ accompanied by a $2 \%$ weight loss ascribed to the decomposition of the organic species of the materials included in the pearl powder. The exothermic peak at $439^{\circ} \mathrm{C}$ is due to the aragonite to calcite transformation of the $\mathrm{CaCO}_{3}$ nanoparticles. During the heating from 580 to $750^{\circ} \mathrm{C}$, the weight loss and exothermic peak around $741^{\circ} \mathrm{C}$ are ascribed to the decomposition of $\mathrm{CO}_{2}$.

(2) X-ray diffraction (XRD), Fourier transform infrared (FTIR) absorption spectra, and analysis showed further evidence that pearls can induce the formation of an HA layer on their surface in SBF, even for short soaking periods.

(3) Nanograde pearl powders induced the formation of apatite layer on their surface after soaking in SBF for $4 \mathrm{~h}$, which demonstrates the excellent in vitro bone forming bioactivity of nanograde pearls.

(4) The cytotoxicities of pearls were tested by the filtration and culture of NIH-3T3 mouse embryonic fibroblast cells. The viability of the cultured cells in media containing pearl crystallites for 24 and $72 \mathrm{~h}$ is greater than $90 \%$.

(5) Bone cells adhered to the pearl disks, as evidenced by scanning electron micrographs. Specifically, these micrographs of E1 cells were adhered to pearl disks taken over a culture interval of $1 \mathrm{~h}$. The osteoblastic cells shown in these micrographs are elongated, with their alignment predominately along the specimen. The cells shown in these images also appear well attached and cover the surface almost completely after $1 \mathrm{~h}$. It is therefore believed that pearls can facilitate bone cell adhesion.

(6) The pearl nanocrystallites had a positive effect on the osteogenic ability of ALP activity, and this promoted the osteogenic differentiation of MSCs significantly at explanations.

\section{Authors' Contribution}

J.-C. Chen and J.-C. Kung contributed equally to this work.

\section{Acknowledgments}

This work was financially support of a Grant from the National Science Council of Taiwan (NSC 98-2622-E-037001-CC3). The authors also acknowledge the supported by Grants from the Kaohsiung Medical University Hospital (KMUH100-0 M25, KMUH100-0 M51) and Grants from the Kaohsiung Medical University Research Foundation (KMUM110008, KMU-M102006).

\section{References}

[1] P. Westbroek and F. Marin, "A marriage of bone and nacre," Nature, vol. 392, no. 6679, pp. 861-862, 1998.

[2] M. Rousseau, L. Pereira-Mouriès, M. J. Almeida, C. Milet, and E. Lopez, "The water-soluble matrix fraction from the nacre of Pinctada maxima produces earlier mineralization of 
MC3T3-E1 mouse pre-osteoblasts," Comparative Biochemistry and Physiology B, vol. 135, no. 1, pp. 1-7, 2003.

[3] M. Lamghari, M. J. Almeida, S. Berland et al., "Stimulation of bone marrow cells and bone formation by nacre: in vivo and in vitro studies," Bone, vol. 25, no. 2, pp. 91S-94S, 1999.

[4] I. M. Weiss, W. Göhring, M. Fritz, and P. K. Mann, "Perlustrin, a Haliotis laevigata (abalone) nacre protein, is homologous to the insulin-like growth factor binding protein $\mathrm{N}$-terminal module of vertebrates," Biochemical and Biophysical Research Communications, vol. 285, no. 2, pp. 244-249, 2001.

[5] G. Atlan, N. Balmain, S. Berland, B. Vidal, and E. Lopez, "Reconstruction of human maxillary defects with nacre powder: histological evidence for bone regeneration," Comptes Rendus de l'Academie des Sciences III, vol. 320, no. 3, pp. 253258, 1997.

[6] C. M. Zaremba, D. E. Morse, S. Mann, P. K. Hansma, and G. D. Stucky, "Aragonite-hydroxyapatite conversion in gastropod (abalone) nacre," Chemistry of Materials, vol. 10, no. 12, pp. 38133824, 1998.

[7] G. Atlan, O. Delattre, S. Berland et al., "Interface between bone and nacre implants in sheep," Biomaterials, vol. 20, no. 11, pp. 1017-1022, 1999.

[8] H. Liao, H. Mutvei, M. Sjöström, L. Hammarström, and J. $\mathrm{Li}$, “Tissue responses to natural aragonite (Margaritifera shell) implants in vivo," Biomaterials, vol. 21, no. 5, pp. 457-468, 2000.

[9] H. Liao, C. Brandsten, C. Lundmark, T. Wurtz, and J. Li, "Responses of bone to titania-hydroxyapatite composite and nacreous implants: a preliminary comparison by in situ hybridization," Journal of Materials Science, vol. 8, no. 12, pp. 823-827, 1997.

[10] E. Lopez, B. Vidal, S. Berland, S. Camprasse, G. Camprasse, and C. Silve, "Demonstration of the capacity of nacre to induce bone formation by human osteoblasts maintained in vitro," Tissue and Cell, vol. 24, no. 5, pp. 667-679, 1992.

[11] C. Silve, E. Lopez, B. Vidal et al., "Nacre initiates biomineralization by human osteoblasts maintained in vitro," Calcified Tissue International, vol. 51, no. 5, pp. 363-369, 1992.

[12] M. J. Almeida, C. Milet, J. Peduzzi et al., "Effect of water-soluble matrix fraction extracted from the nacre of Pinctada maxima on the alkaline phosphatase activity of cultured fibroblasts," Journal of Experimental Zoology, vol. 288, pp. 327-334, 2000.

[13] M. Ni and B. D. Ratner, "Nacre surface transformation to hydroxyapatite in a phosphate buffer solution," Biomaterials, vol. 24, no. 23, pp. 4323-4331, 2003.

[14] Y. Shen, J. Zhu, H. Zhang, and F. Zhao, "In vitro osteogenetic activity of pearl," Biomaterials, vol. 27, no. 2, pp. 281-287, 2006.

[15] M. Suzuki, K. Saruwatari, T. Kogure et al., "An acidic matrix protein, Pif, is a key macromolecule for nacre formation," Science, vol. 325, no. 5946, pp. 1388-1390, 2009.

[16] N. Kröger, "The molecular basis of nacre formation," Science, vol. 325, no. 5946, pp. 1351-1352, 2009.

[17] T. Kokubo and H. Takadama, "How useful is SBF in predicting in vivo bone bioactivity?" Biomaterials, vol. 27, no. 15, pp. 29072915, 2006. 

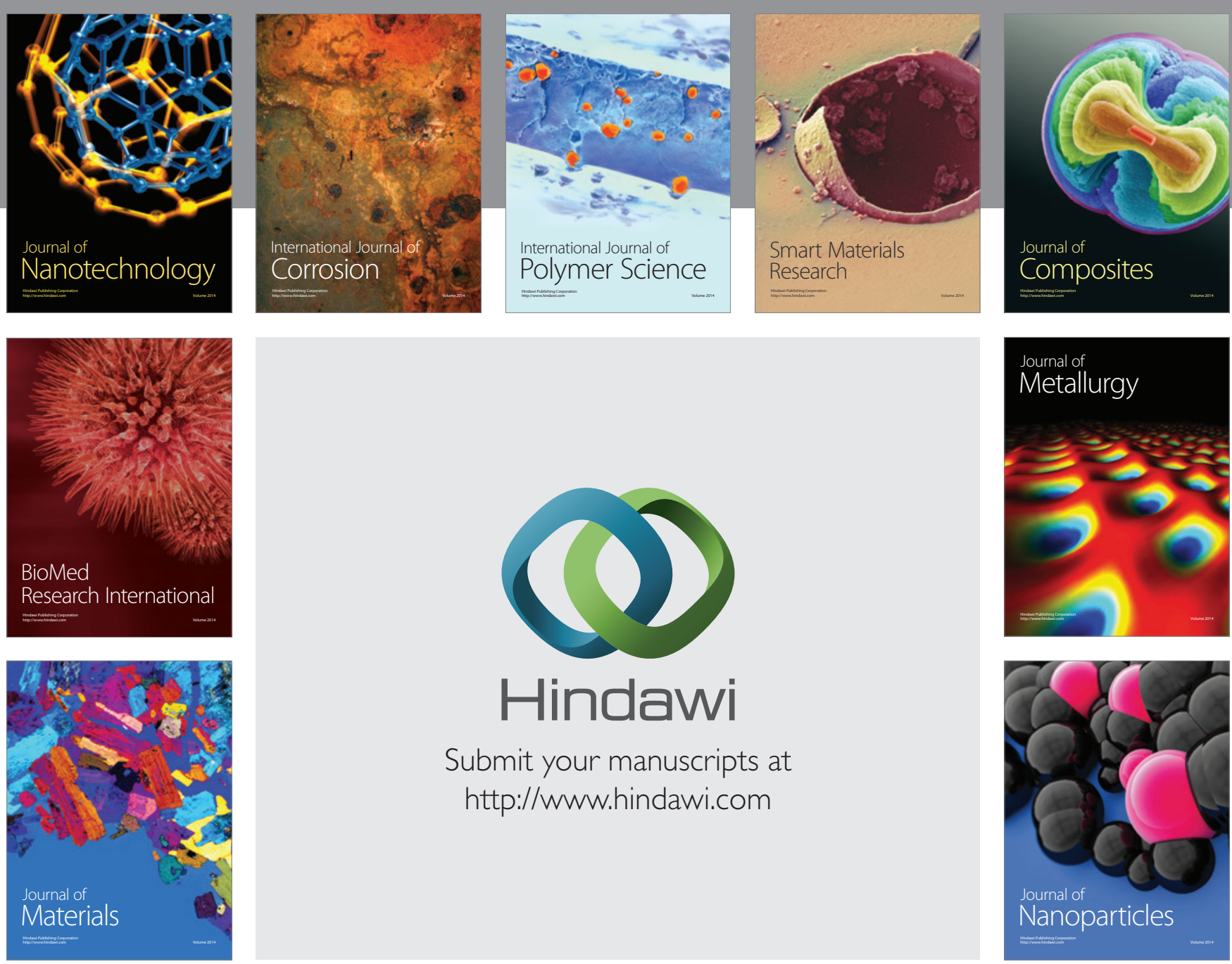

Submit your manuscripts at http://www.hindawi.com
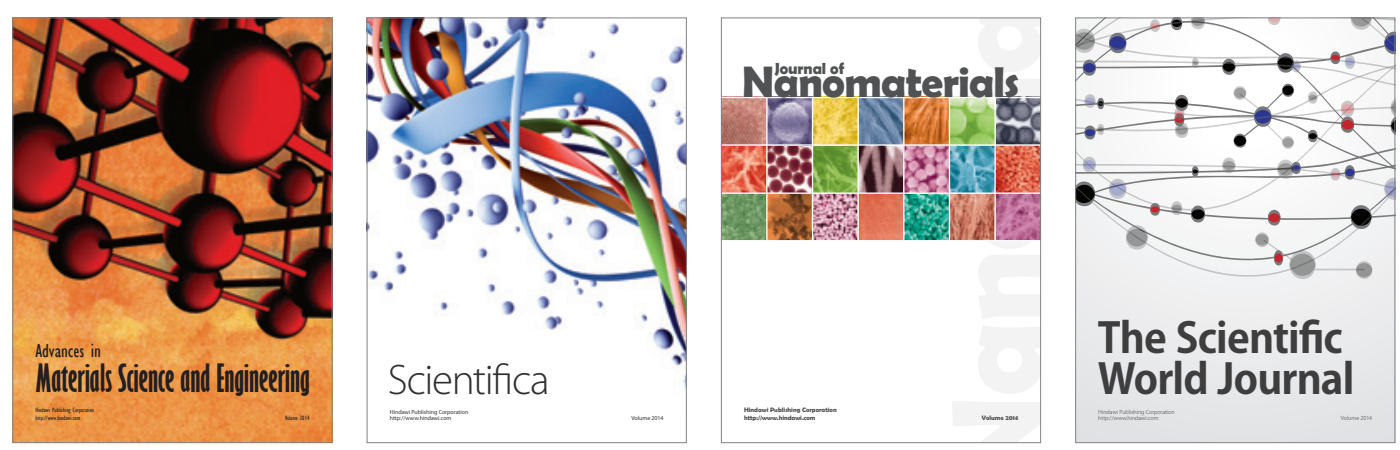

\section{The Scientific World Journal}
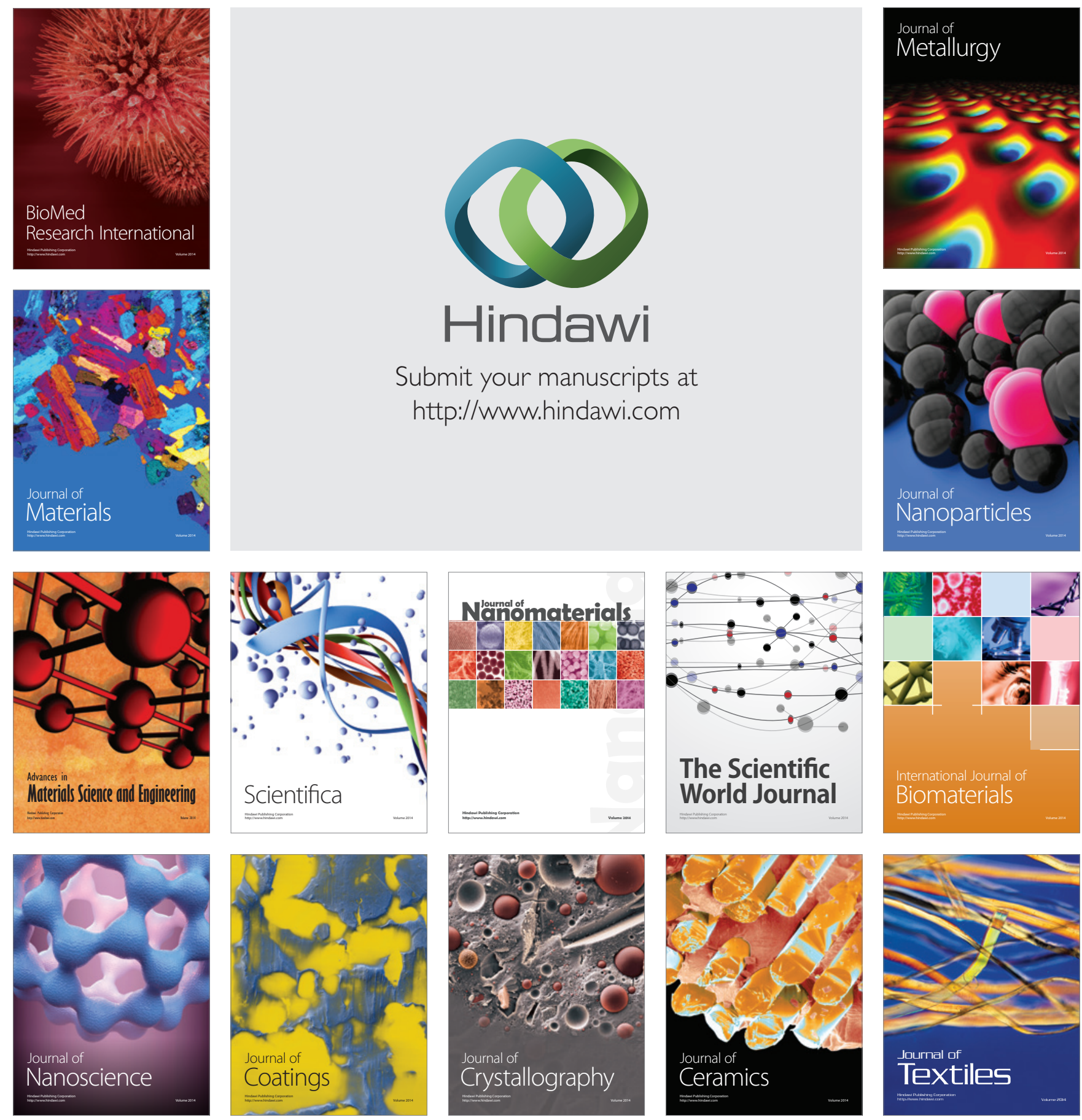